\title{
Comparison of the Effect of Lidocaine versus a Lidocaine-Bupivacaine Combination in a Periprostatic Nerve Block Undergoing Transrectal Ultrasound-Guided Prostate Biopsy: A Double-Blind Randomized Controlled Trial
}

\author{
Ali H. Yilmaz ${ }^{\mathrm{a}}$ Elif Ziypak ${ }^{\mathrm{b}}$ Tevfik Ziypak $^{\mathrm{a}} \quad$ Mehmet Aksoy $^{\mathrm{c}}$ Senol Adanur \\ Hüseyin Kocakgol $^{\mathrm{a}}$ Saban O. Demirdogen ${ }^{\mathrm{a}}$ Ozkan Polat ${ }^{\mathrm{a}}$ \\ a Department of Urology; and 'Department of Anesthesiology and Reamination, Ataturk University Faculty of Medicine; \\ bDepartment of Anesthesiology and Reamination, Education and Research Hospital, Erzurum, Turkey
}

\section{Key Words}

Bupivacaine $\cdot$ Biopsy $\cdot$ Periprostatic nevre block •

TRUS-guided prostate biopsy

\begin{abstract}
Introduction: To determine whether a combination of the long acting local anesthetic, bupivacaine, and lidocaine is better than lidocaine alone in the long-term pain control, which is a short-acting anesthetic. Materials and Methods: In group 1, periprostatic nerve block was applied to both neurovascular areas with $2 \%$ lidocaine $(5 \mathrm{ml})$ in an isotonic solution $(5 \mathrm{ml})$. In group 2 , the combination of $2 \%$ lidocaine $(5 \mathrm{ml})$ and $5 \mathrm{mg} / \mathrm{ml}$ bupivacaine $(5 \mathrm{ml})$ was used for the PPNB. Results: In the first 30 minutes the mean VAS scores of groups 1 and 2 were $2.1 \pm 0.2$ and $1.2 \pm 0.1$, respectively $(p=$ 0.002 ). VAS scores of group II determined at $1,2,4,6$, and 8 hours after the biopsy were significantly lower since it was ( $p$ $<0.05$ ). Conclusion: While periprostatic nerve block for late phase pain control, applying a combination of a long-acting local anesthetic, such as bupivacaine, is effective in terms of pain control and patient comfort. Copyright $\odot 2015 \mathrm{~S}$. Karger AG, Basel
\end{abstract}

\section{KARGER}

Fax +4161306 1234

E-Mail karger@karger.ch

www.karger.com
(C) 2015 S. Karger AG, Basel

1015-9770/15/0093-0153\$38.00/0

Accessible online at:

www.karger.com/cur

\section{Introduction}

Prostate cancer $(\mathrm{PCa})$ is the most common cancer in males in Western countries [1]. A prostate biopsy was first performed in the 1930s under the guidance of the fingers; biopsies were later performed through a transperineal approach and finally a transrectal procedure as defined by Astraldi [2]. The factors causing pain during a prostate biopsy include: entry of a transrectal ultrasound (TRUS) probe into the rectum, the TRUS probe interior movements, the size and geometry of the probe, the passing of a needle through both the rectal wall and prostate capsule, and pains associated with retrieving core biopsies.

The apex of the prostate is reported to be the most painful area during the biopsy. The reason for this is because the innervation of the anorectal mucosa under the dentate line is predominantly somatic nervous tissue [3]. During a prostate biopsy, since biopsy needles pass through the rectal wall over the dentate line, where sensations are reduced, the majority of pain is associated with the penetration of the needle into the capsule of the pros- 
tate. The nerve fibers originating from the presacral and hypogastric plexus are divided into branches of the prostatic plexus and they have a course along with prostatic vascular pedicles. Posterolateral nerve fibers are believed to be the main source of innervation for the prostate [4]. Direct contact of the needle with nerves may also cause pain [5].

Prostate biopsies have been performed using various methods of anesthesia and analgesia. Intrarectal local anesthesia, periprostatic nerve block, intraprostatic anesthesia, pelvic plexus block, a caudal block, and a pudendal nerve block are some of the methods used. Additionally, nonsteroidal anti-inflammatory drugs, tramadol, propofol, midazolam, and azote oxide + oxygen, are used for analgesia and anesthesia. Among these, the most commonly used methods are periprostatic nerve blocks and rectal lidocaine gel applications [6-10]. Current protocols suggest the combination of periprostatic nerve block (PPNB) and intrarectal local anesthesia before prostate biopsy as these provide a very effective pain control during the biopsy.

\section{Materials and Methods}

After obtaining ethical approval, a total of 200 patients who had undergone a TRUS-guided biopsy were included in the study. All patients were included in the program due to an abnormal digital rectal examination and/or an elevated PSA level ( $\geq 4 \mathrm{ng}$ / $\mathrm{ml})$. Patients with neurological disorders causing reduced perianal and/or rectal sensations, those with an allergy against lidocaine or other drugs, or pathologies that could increase the pain associated with a biopsy, such as an anal fissure, were excluded from the study. The medications of patients taking aspirin and anticoagulants were discontinued a week prior to the biopsy procedure. After determining the need for a prostate biopsy and receiving patients' standard informed consent forms, the patients were informed about the details of the study. A second consent form was taken from patients who had agreed to participate in the study voluntarily. A periprostatic nerve block was used as the method of anesthesia and was applied by an injection into the angle between the bilateral basal prostate and the seminal vesicles.

Patients were randomly divided into 2 groups. In Group I, periprostatic block was applied to both neurovascular areas with $2 \%$ lidocaine $(5 \mathrm{ml})$ in an isotonic solution $(5 \mathrm{ml})$. In Group 2, the combination of $2 \%$ lidocaine $(5 \mathrm{ml})$ and $5 \mathrm{mg} / \mathrm{ml}$ bupivacaine $(5$ $\mathrm{ml}$ ) was used for the PPNB. Both anesthetic solutions used in this study had the same color and amount $10 \mathrm{ml}$. The anesthetic content was unknown to both the biopsy patients and the urologists. The biopsy and patient follow ups were performed by the same urologist (A.H.Y). The solutions were prepared in a separate environment by a nurse. TRUS and biopsy processes were performed with a fully automatic biopsy needle by using the endoprobe (we used end fire probe) from a General Electric LOGIQ P5 brand reasonably sized ultrasound device at $6.5 \mathrm{MHz}$, while the patient was in the left lateral decubitus position with flexed knees and hip. The patients took $2 \mathrm{~g}$ cefazolin $30 \mathrm{~min}$ prior to the biopsy for prophylaxis and used $500 \mathrm{mg}$ ciprofloxacin and $500 \mathrm{mg}$ metronidazole for 5 days following biopsy procedure. The patient comfort is an important factor in TRUS-guided prostate biopsy. We performed patient preparation and positioning as the guidelines. We used lubrications for instruments when probe placing. We also used topical anesthesia with prilocaine-lidocaine cream applied to the anal ring. A PPNB was performed 5 minutes before the biopsy procedure. A 22-gauge Chiba needle was used for the anesthetic injection. After placing the probe, the prostate's transverse and sagittal planes were monitored and the prostate volume was measured. Asymmetry or hypoechoic areas were determined. The biopsy procedure was performed with a BARD brand 18-gauge 25$\mathrm{cm}$ fully automatic Tru-Cut biopsy needle. Patients were asked to define the pain with a 10-point visual analog scale (VAS), which had previously been explained to them in detail. The duration of the biopsy procedure was determined as the time spent between placing the probe and later removing the probe after completing the last biopsy. The pain inquiry was performed while placing the probe, taking the biopsy, at 30 minutes, at 1 hour, 2 hours, 4 hours, and at 8 hours after the procedure by VAS scoring. After 8 hours the patients were asked if another biopsy could be performed, if needed.

Complications at 8 hours and 48 hours (e.g., anal bleeding, hematuria, infection) following the biopsy procedure were examined. But following days those complications were treated easily. Statistical analyses were performed with SPSS software for Windows 17. Pearson's chi-square test, Fisher's chi-square test, and a Mann-Whitney $\mathrm{U}$ test were used in the statistical analyses. A p-value of $<0.05$ was considered statistically significant. The adequacy of the number of patients was assessed by a power analysis.

\section{Results}

In Group 1 (lidocaine), there were a total of 91 patients with a mean age of $68.8 \pm 1.1$ years. In Group 2 (lidocaine + bupivacaine), there were 109 patients with a mean age of $68.1 \pm 0.9$ years. In Group 1, 14-core extended biopsies were taken from 87 patients, and 24-core saturation biopsies were taken from 4 patients whose first biopsy came either atypical small acinar proliferation (ASAP) or prostatic intraepithelial neoplasia (PIN). In Group 2, 14-core extended biopsies were taken from 102 patients and 24-core saturation biopsies were taken from seven patients whose first biopsy came was determined ASAP or PIN. Additionally, the mean prostate volumes of patients in Group 1 and 2 were $90.6 \pm 5.6 \mathrm{ml}$ and 83.8 $\pm 4.2 \mathrm{ml}$, respectively. The mean PSA values for Group 1 and 2 were $21.2 \pm 3.5 \mathrm{ng} / \mathrm{ml}$ and $27.6 \pm 3.9 \mathrm{ng} / \mathrm{ml}$, respectively. The average biopsy time in both groups was $4.2 \mathrm{~min}$. There were similarities between groups in terms of PSA values, prostate volume, biopsy time, and demographic data. Prostate volumes of the patients by groups, 
Table 1. Distribution of the mean prostate volumes, PSA levels, biopsy durations, and patient demographic data by groups

\begin{tabular}{lrl}
\hline & $\mathrm{N}$ & Means \\
\hline $\begin{array}{l}\text { Age (years) } \\
\quad \text { Lidocaine }\end{array}$ & 91 & \\
$\quad$ Lidocaine + Bupivacaine & 109 & $68.8 \pm 1.1$ \\
$\begin{array}{l}\text { Prostate Volume (ml) } \\
\quad \text { Lidocaine }\end{array}$ & 91 & $68.1 \pm 0.9$ \\
$\quad$ Lidocaine + Bupivacaine & 109 & $90.6 \pm 5.6$ \\
$\begin{array}{l}\text { PSA (ng/ml) } \\
\quad \text { Lidocaine }\end{array}$ & 91 & $83.8 \pm 4.2$ \\
$\quad$ Lidocaine + Bupivacaine & 109 & $21.2 \pm 3.5$ \\
Height (m) & & $27.6 \pm 3.9$ \\
$\quad$ Lidocaine & 91 & $1.7 \pm 0.0$ \\
$\quad$ Lidocaine + Bupivacaine & 109 & $1.7 \pm 0.0$ \\
Weight (kg) & & $74.5 \pm 1.3$ \\
$\quad$ Lidocaine & 91 & $75.4 \pm 1.2$ \\
$\quad$ Lidocaine + Bupivacaine & 109 & $4.1 \pm 0.1$ \\
$\quad$ Biopsy Time (min) & & $4.1 \pm 0.1$ \\
$\quad$ Lidocaine & 91 & \\
$\quad$ Lidocaine + Bupivacaine & 109 & \\
\end{tabular}

PSA, biopsy duration, patient age, patient weight, mean patient height, and standard deviations are summarized in table 1.

From the first moment of placing the probe, mean VAS scores of patients in Group 1 and 2 were $3.05 \pm 0.2$ and $2.7 \pm 0.2$, respectively. During the biopsy, the mean VAS scores were $2.6 \pm 0.2$ and $2.3 \pm 0.3$ in Groups 1 and 2, respectively. There was no statistically significant difference between groups in terms of VAS scores during the biopsy or while placing the probe $(\mathrm{p}>0.05)$. In the first $30 \mathrm{~min}$ following the biopsy procedure the mean VAS scores of Group I and 2 were $2.1 \pm 0.2$ and $1.2 \pm 0.1$, respectively; this difference was statistically significant ( $\mathrm{p}$ $=0.002$ ). VAS scores of Group 2 determined at 1, 2, 4, 6, and 8 hours after the biopsy were significantly lower than in Group 1 ( $\mathrm{p}=0.001, \mathrm{p}<0.001, \mathrm{p}<0.001, \mathrm{p}=0.001$, and $\mathrm{p}=0.004$, respectively). VAS score comparisons measured while placing the probe, taking the biopsy, and 30 minutes, 1hour, 2 hours, 4 hours, and 8 hours after the procedure by groups and p-values are shown in table 2 .

Patients were also compared based on fourteen core biopsies and 24-core saturation biopsies; no significant difference was found between the groups in terms of the number of biopsies and pain conditions ( $p>0.05$ ). Patients were examined at 8 and 48 hours in terms of complications including anal bleeding, hematuria, and infection; the groups were then compared in terms of complication ratios. Some of these complications in one

Lidocaine versus a Combination in Periprostatic Nerve Block
Table 2. The mean VAS scores by groups during and after the biopsy and p-values showing the statistical differences

\begin{tabular}{|c|c|c|c|}
\hline VAS Evaluation Time & $\mathrm{N}$ & Means & $\mathrm{p}$ \\
\hline While placing the probe & & & $>0.05$ \\
\hline Lidocaine & 91 & 3.05 & \\
\hline Lidocaine + Bupivacaine & 109 & 2.70 & \\
\hline During the biopsy & & & $>0.05$ \\
\hline Lidocaine & 91 & 2.60 & \\
\hline Lidocaine + Bupivacaine & 109 & 2.38 & \\
\hline 30 minutes & & & 0.002 \\
\hline Lidocaine & 91 & 2.19 & \\
\hline Lidocaine + Bupivacaine & 109 & 1.24 & \\
\hline 1 hour & & & 0.001 \\
\hline Lidocaine & 91 & 2.00 & \\
\hline Lidocaine + Bupivacaine & 109 & 0.95 & \\
\hline 2 hours & & & $<0.001$ \\
\hline Lidocaine & 91 & 1.79 & \\
\hline Lidocaine + Bupivacaine & 109 & 0.59 & \\
\hline 4 hours & & & $<0.001$ \\
\hline Lidocaine & 91 & 1.38 & \\
\hline Lidocaine + Bupivacaine & 109 & 0.39 & \\
\hline 6 hours & & & 0.001 \\
\hline Lidocaine & 91 & 0.99 & \\
\hline Lidocaine + Bupivacaine & 109 & 0.19 & \\
\hline 8 hours & & & 0.004 \\
\hline Lidocaine & 91 & 0.86 & \\
\hline Lidocaine + Bupivacaine & 109 & 0.19 & \\
\hline
\end{tabular}

VAS $=$ Visual analog scale

patient; high fever, in 12 patients (13\%); anal bleeding and hematuria, in 17 (18\%) patients; only hematuria, in 4 patients (4\%) anal bleeding was observed only. No complications were observed in 57 (62\%) patients in Group 1. In Group 2, no fever was observed in any of the patients. Anal bleeding and hematuria was seen in $11(10 \%)$ patients, hematuria in 21(19\%) patients, and anal bleeding only was found in $5(4 \%)$ patients. In the other 72 patients $(66 \%)$, no complications were found. There were no statistically significant differences between groups in terms of complication development ( $p>0.05)$.

Group 1 patients were asked if they would accept a re-biopsy in case of a medical necessity; from this, they were classified into 3 groups. There were 65 (71\%) patients in Group 1 who approved of a re-biopsy, if needed; however, $23(25 \%)$ patients did not approve. The remaining 3 (3\%) patients had not decided. In Group 2, 85 (78\%) patients approved of a re-biopsy if needed; and 21 (19\%) patients did not approve. The remaining $3(3 \%)$ patients had not decided. There was no statically significant difference between Group 1 and 2 in terms of the number of the patients either accepting or not accepting a re-biopsy $(p>0.05)$. 
According to the statistical analyses, the adequacy of the number of patients to achieve this data was evaluated by a power analysis and found to be sufficient with a ratio of $96 \%$ to $99 \%$.

\section{Discussion}

During a prostate biopsy with transrectal ultrasonography, patients realize they are experiencing physical and psychological traumas. According to clinical experiences, this procedure is remarkably painful and many people have refused to undergo this procedure [11]. The pain experienced during a prostate biopsy leads to a cumulative increase in total pain in relation with the number of cores taken [7]. According to many studies, $65-90 \%$ of patients feel nervous about a sextant prostate biopsy without anesthesia, and 30\% of patients feel considerably high amounts of pain [5, 12]. A sextant biopsy performed without anesthesia is a very painful and uncomfortable procedure. However, the expanded 12-core prostate biopsy performed without anesthesia leads to a pain that is described as similar to that caused by torture. Therefore, samples cannot be taken properly and patients leave the procedure before the completion of the operation process $[3,11]$.

Pain is a subjective sensation and is therefore, very difficult to measure. Pain perception and resistance are subjective with variations from person to person. The pain associated with a prostate biopsy is a complex phenomenon with a physical and psychological nature [3]. Good pain control after a prostate biopsy can prevent negative outcomes including tachycardia, hypertension, and myocardial ischemia. During a prostate biopsy, pain may result from the following: placement of the biopsy probe, taking a biopsy, and injection for a PPNB $[13,14]$. In a prostate biopsy, one of the major challenges for studies regarding anesthesia methods is determining the pain felt by patients. For this purpose, the most preferred pain scoring system is the VAS method that we used in our study [15].

Patients who underwent a first biopsy without anesthesia and received a PPNB in the second procedure state that there was a significant pain reduction when the PPNB was applied [8]. Furthermore, their need for anesthesia after the procedure also decreased. Leibovici et al. [16] showed that this technique is safe and easy to apply. A PPNB was defined for the first time for the basal injection technique by Nash in 1996 [7]. In this technique, Nash describes the PPNB being applied to the area where nerves are close to the prostate and they are not yet branched. The fatty tissue located between the seminal vesicles and prostate gives a hyperechoic image with ultrasonography. There are those who call this area as "mount Everest" [17]. Walker et al. [18] have examined pericapsular lidocaine injections to the apex of the prostate and showed its effectiveness in reducing pain in TRUS-guided prostate biopsies. We preferred to apply injections to the angle between the bilateral basal prostate and the seminal vesicles in accordance with the description given by Nash [7]. However, according to the European Association of Urology guidelines, there is no difference between making the injection at either the basal prostate or apex of the prostate [19].

An injection for a complete nerve block should be performed symmetrically on both sides as we have done in our study [20]. However, there are authors that have suggested one-sided injections. In some centers, the implementation of an intrarectal lidocaine gel during a TRUSguided biopsy has become a standard procedure. Since lidocaine gel was applied to all patients in our study, it was not possible to have a comparative result in this matter. However, based on our experience, we suggest that lidocaine gel may have a positive effect on pain while both placing the probe and during the anesthetic injection.

According to a study with 75 patients by Rabets et al. [21], patients were divided into 3 groups: the first group did not receive anesthesia, the second group received bupivacaine only for periprostatic block, and the third group received a combination of lidocaine and bupivacaine. There was no difference between the second and third groups in terms of pain control. However, there were significant differences in both the second and third groups compared to the first Group in terms of pain control. Moreover, unlike our study, only pain during the biopsy was examined, and long term pain was not examined. It can be criticized that no anesthesia was given to the patients of the first group during such a traumatic procedure. The number of patients included in the study can be considered another issue that can be criticized. It should also be noted that lidocaine was effective in the first half hour and during the biopsy for pain control. If long-term pain was examined when a long-acting anesthetic (bupivacaine) was used, this study would have been more meaningful. Bupivacaine is a long-acting local anesthetic; however, its effect starts later compared to the effect of lidocaine [22]. In the second group, having pain control during the biopsy similar to the third Group is another debatable result of the study. In a study by Lee-Elliot et al. [23], lidocaine and a combination of 
lidocaine + bupivacaine were compared. This group reported that VAS scores were examined by a survey during the biopsy, at the first hour, and during the next 7 days. They reported that the combination of lidocaine + bupivacaine gives better results for pain control over long-term periods. This study has a particular importance since it shows that pain can last for one week after a prostate biopsy [23]. However, there were no follow-ups after the first hour of the biopsy, and the follow-up examinations between the first and seventh days were made by correspondence. The most intense pain associated with a prostate biopsy is felt during the biopsy procedure and these levels decrease thereafter. Therefore, we monitored our patients for 8 hours after the procedure and recorded their VAS scores to evaluate the late effects of local anesthesia. In our study, similar to the study of Lee-Elliot et al., we found there was no significant difference between the long-acting local anesthetic combination group and the lidocaine Group in terms of VAS scores during the biopsy. However, when we examined long-term pain, the combination of lidocaine and bupivacaine was significantly better than with only lidocaine. Most studies have focused on pain experience during the procedure. However, a significant portion of patients also feel pain after the procedure. The number of studies related to examining pain after the procedure is insufficient to discuss our long-term pain symptoms. In this sense, we think that our study provides an important contribution to the literature. In this study, we have demonstrated that the combination of a long-acting anesthetic, such as bupivacaine, is effective in the late phase of pain control.

Re-biopsies are issues that cause anxiety for both the patient and urologist in the presence of ASAP, PIN, and actively monitored patients diagnosed with prostate cancer. The success of the anesthesia is important in reducing anxiety during the first biopsy. In our study, $65(71 \%)$ patients in Group 1 and 85 (78\%) in Group 2 approved of having a re-biopsy; there was no statistical difference between groups in terms of approving a re-biopsy. Although the effect of long-acting local anesthesia in long-term pain control was shown, the pain during the procedure affects a patient's behavior more in terms of a re-biopsy.

\section{Conclusion}

PPNB is an easy and reliable technique that has become almost standard in prostate biopsies. This method is extremely advantageous in terms of pain control and patient comfort for outpatients in particular. In PPNB, the most commonly used local anesthetic agent is lidocaine. However, while periprostatic nerve blocks are for late phase pain control, applying a combination of a long-acting local anesthetic, such as bupivacaine, is effective in terms of pain control and patient comfort. Bupivacaine is an easily-accessed and inexpensive local anesthetic that is also reliable in terms of side effects. Preparing and applying a combination of local anesthetics in a prostate biopsy does not change the duration of the procedure and does not make the procedure technically more difficult; however, they have a significant positive effect on pain control. Based on the data we have received from this study, we think we can recommend the combination of lidocaine and bupivacaine to be used routinely in PPNB.

\section{Ethical Approval}

All procedures performed in studies involving human participants were in accordance with the ethical standards.

\section{Ethics Committee Approval}

İRB approved protocol number 23.01.2014/2/14. 


\section{References}

1 Siegel R, Naishadham D, Jemal A: Cancer statistics, 2012. CA Cancer J Clin 2012;62: 10-29.

2 Astraldi A: Diagnosis of cancer of the prostate: biopsy by rectal route. Urol Cutaneous Rev 1937;41-42.

3 Bastide C, Lechevallier E, Eghazarian C, Ortega JC, Coulange C: Tolerance of pain during transrectal ultrasound-guided biopsy of the prostate: risk factors. Prostate Cancer Prostatic Diseases 2003;6:239-241.

4 Clements R, Aideyan OU, Griffiths GJ, Peeling WB: Side effects and patient acceptability of transrectal biopsy of the prostate. Clin Radiol 1993;47:125-126.

5 Collins GN, Lloyd SN, Hehir M, McKelvie GB: Multiple transrectal ultrasound-guided prostatic biopsies--true morbidity and patient acceptance. Br J Urol 1993;71:460-463.

6 Irani J, Fournier F, Bon D, Gremmo E, Dore $\mathrm{B}$, Aubert J: Patient tolerance of transrectal ultrasound-guided biopsy of the prostate. $\mathrm{Br}$ J Urol 1997;79:608-610.

7 Nash PA, Bruce JE, Indudhara R, Shinohara $\mathrm{K}$ : Transrectal ultrasound guided prostatic nerve blockade eases systematic needle biopsy of the prostate. J Urol 1996;155:607609.

8 Soloway MS, Öbek C: Periprostatic local anesthesia before ultrasound guided prostate biopsy. J Urol 2000;163:172-173.

9 Pareek G, Armenakas NA, Fracchia JA: Periprostatic nerve blockade for transrectal ultrasound guided biopsy of the prostate: a randomized, double-blind, placebo controlled study. J Urol 2001;166:894-897.
10 Alavi AS, Soloway MS, Vaidya A, Lynne CM, Gheiler EL: Local anesthesia for ultrasound guided prostate biopsy: a prospective randomized trial comparing 2 methods. J Urol 2001;166:1343-1345.

11 Crundwell MC, Cooke PW, Wallace DM: Patients' tolerance of transrectal ultrasound-guided prostatic biopsy: an audit of 104 cases. BJU Int 1999;83:792-795.

12 Clements R: Ultrasound-guided prostate biopsy in 2005. Clin Radiol 2006;61:140-141.

13 Schostak M, Christoph F, Muller M, Heicappell R, Goessl G, Staehler M, Miller K: Optimizing local anesthesia during 10-core biopsy of the prostate. Urology 2002;60:253257.

14 Inal G, Yazici S, Adsan O, Ozturk B, Kosan M, Cetinkaya M: Effect of periprostatic nevre blockade before transrectal ultrasound-guided prostate biopsy on patient comfort: a randomized placebo controlled study. Int J Urol 2004;11:148-151.

15 Scott J, Huskisson EC: Graphic representation of pain. Pain1976;2:175-184.

16 Leibovici D, Zisman A, Siegel YI, Sella A, Kleinmann J, Lindner A: Local anesthesia for prostate biopsy by periprostatic lidocain einjection: a double-blind placebo controlled study. J Urol 2002;167:563-565.

17 Jones JS, Oder M, Zippe CD: Saturation prostate biopsy with periprostatic block can be performed in the office. J Urol 2002;168: $2108-2110$
18 Walker AE, Schelvan C, Rockall AG, Rickards D, Kellett MJ: Does pericapsular lidocaine reduce pain during transrectal ultrasonography-guided biopsy of the prostate? BJU Int 2002;90:883-886.

19 Heidenreich A, Bastian PJ, Bellmunt J, Bolla $\mathrm{M}$, Joniau S, van der Kwast $\mathrm{T}$, Mason $\mathrm{M}$, Matveev V, Wiegel T, Zattoni F, Mottet N: EAU guidelines on prostate cancer. Part II: treatment of advanced, relapsing, and castration-resistant prostate cancer. Eur Urol 2014; 65:467-479.

20 Nazir B: Pain during transrectal ultrasound-guided prostate biopsy and the role of periprostatic nerve block: what radiologists should know. Korean J Radiol 2014;15:543553.

21 Rabets JC, Jones JS, Patel AR, Zippe CD: Bupivacaine provides rapid, effective June periprostatic anaesthesia for transrectal prostate biopsy. BJU Int 2004;93:1216-1217.

22 McLeod GA, Butterworth JF IV, Wildsmith JA: Local anesthetic systemic toxicity; in Cousins MJ, Carr DB, Horlocker TT, Bridenbaugh PO (eds): Cousins and Bridenbaugh's Neural Blockade in Clinical Anesthesia and Pain Medicine, 4 ed. Philadelphia, Lippincott Williams Wilkins, 2009, pp114-116.

23 Lee-Elliott CE, Dundas D, Patel U: Randomized trial of lidocaine vs lidocaine/bupivacaine periprostatic injection on longitudinal pain scores after prostate biopsy. J Urol 2004;171:247-250. 